\title{
Inactivity of imatinib in gastrointestinal stromal tumors (GISTs) harboring a KIT activation-loop domain mutation (exon 17 mutation pN822K)
}

This article was published in the following Dove Press journal:

OncoTargets and Therapy

18 August 2015

Number of times this article has been viewed

\author{
Gianluca Spitaleri' \\ Roberto Biffi ${ }^{2}$ \\ Massimo Barberis ${ }^{3}$ \\ Caterina Fumagalli ${ }^{3}$ \\ Francesca Toffalorio' \\ Chiara Catania' \\ Cristina Noberasco' \\ Chiara Lazzari' \\ Filippo de Marinis' \\ Tommaso De Pas ${ }^{4}$ \\ 'Division of Chest Medical Oncology, \\ ${ }^{2}$ Division of Abdominal Surgery, \\ ${ }^{3}$ Division of Pathology, ${ }^{4}$ Oncology \\ Unit of Thymic cancer, Rare Tumors \\ and Sarcomas, European Institute of \\ Oncology, Milan, Italy
}

\begin{abstract}
The development of gastrointestinal stromal tumors (GISTs) is largely driven by mutations in the KIT and PDGFR $\alpha$ genes. Imatinib mesylate is an oral small molecular tyrosine kinase inhibitor that mainly targets $a b l, c-K I T$, and $P D G F R \alpha$. Imatinib achieves disease control in approximately $70 \%-85 \%$ of patients with advanced GIST, and the median progression-free survival is 20-24 months. The efficacy of imatinib correlates with tumor kinase mutational status (exon 11 mutations mainly), and some mutations are known to be responsible for primary and secondary imatinib resistance. Beyond these, there are many other mutations that are considered rare and are associated with unknown clinical behavior. In the literature, there are poor and inconsistent data about the inhibitor sensitivity of mutations occurring in the activation-loop domain encoded by exon 17. In this article, we focus on a case of a patient suffering from GIST, harboring an extremely rare KIT activation-loop domain mutation (exon 17 mutation pN822K) treated with imatinib. A review of the literature is also presented.
\end{abstract}

Keywords: GIST, KIT activation-loop domain mutation, drug resistance, imatinib

\section{Introduction}

Gastrointestinal stromal tumors (GISTs) are the most common mesenchymal tumors of the gastrointestinal tract. ${ }^{1}$ At diagnosis, majority of the tumors are resectable, but approximately $50 \%$ of these cases recur. ${ }^{2}$ The most common sites of primary disease are the stomach $(60 \%)$ and small intestine $(25 \%){ }^{3}$ Histologically, GISTs have a wide range of morphologies (from spindle cell to epithelioid), but the diagnosis requires an immunopositivity for KIT $(C D 117)^{4}$ or DOG1. ${ }^{5}$ Most GISTs, but not all, harbor mutations of KIT (approximately $75 \%$ of cases) ${ }^{6}$ or $P D G F R \alpha$ (approximately $5 \%-8 \%)^{7}$

Imatinib mesylate is an oral small molecular inhibitor of tyrosine kinases; it mainly targets $a b l, c-K I T$, and PDGFR $\alpha .{ }^{8}$ Imatinib achieves disease control in approximately $70 \%-85 \%$ of patients with advanced GIST, and the median progression-free survival is 20-24 months with a median survival of 5 years. ${ }^{910}$ The spectrum of activity of imatinib is strongly affected by the driver mutations that the tumor harbors and, in particular, the juxtamembrane domain mutations (encoded by exon 11) are the most sensitive, while the extracellular domain mutations (exon 9) require a higher dose of imatinib to achieve good clinical control. ${ }^{10}$ A subgroup analysis from the ACOSOG Z9001 Trial ${ }^{11}$ (1 year of adjuvant imatinib in a placebo-controlled trial in 645 patients) did not demonstrate that tumor mutation status independently affects relapse-free survival in either the placebo or imatinib arm. In detail, there was a clear benefit of adjuvant imatinib in patients with KIT exon 11 deletions (not KIT exon 11 insertions or point mutations).
Correspondence: Gianluca Spitaleri European Institute of Oncology, Ripamonti 435, 20I4I Milan, Italy

Tel +390257489482

Fax +390294379235

Email gianluca.spitaleri@ieo.it 
However, drug resistance caused by secondary KIT or PDGFRA mutations eventually develops in $90 \%$ of cases. ${ }^{12}$ In addition to these mutations, there are many others that are considered rare and are associated with unknown clinical behavior. In this article, we report a case of a patient suffering from GIST harboring a rare KIT activation-loop domain mutation (exon 17 mutation $\mathrm{pN} 822 \mathrm{~K}$ ) treated with imatinib.

\section{Case report}

In November 2009, a 48-year-old Philippine man without relevant comorbidities was admitted to an Asian hospital to undergo surgical resection of a high-risk ileal $10 \mathrm{~cm}$ GIST.

After surgery, he moved to Italy and came to our institute for a second opinion. Tumor tissues for the molecular analysis to sequence $c-K I T$ were not available, so he was treated with a 1-year adjuvant treatment with imatinib at a daily dose of $400 \mathrm{mg}$ daily, according to 2009 international guidelines.

On October 2012, a follow-up abdominal computed tomography (CT) scan detected a $45 \times 32 \mathrm{~mm}$ unique local relapse, and treatment with $400 \mathrm{mg}$ a day imatinib was administered again. A tumor biopsy was not performed due to the patient's refusal.

A CT scan performed after 6 weeks from imatinib onset showed that the lesion increased in size, with no areas of reduced contrast enhancement. Imatinib dosage was then increased to $800 \mathrm{mg}$ a day, but a subsequent CT scan performed after 6 weeks showed no signals of treatment response. The lesion was unique at CT scan and was amenable to radical surgery; on February 27, 2013, the patient underwent surgical disease excision. A large implant of recurrent GIST was visible on the peritoneal surface of the abdominal wall, $8.5 \mathrm{~cm}$ in longitudinal diameter. It was apparently increased with respect to the previous CT scan, despite the fact that the patient had not interrupted imatinib administration. An enlarged epiploic appendix of the sigmoid

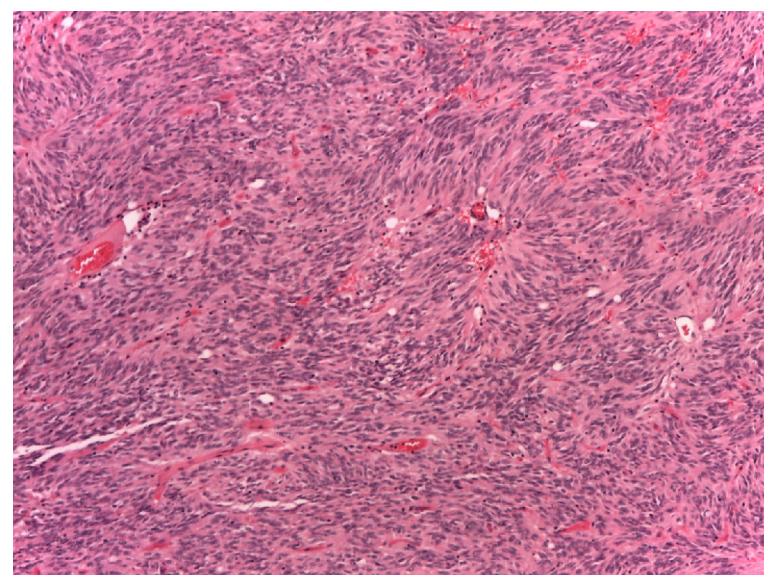

Figure I The tumor was composed of a monotonous spindle-cell proliferation. Notes: Hematoxylin and eosin stain; original magnification: $10 \times$.

colon was removed for histology, and a peritoneal washing was performed for cytology. The recurrent lesion was eventually radically removed, together with the adherent omentum, taking care not to open the lining capsule surrounding it.

Macroscopically, the tumor was roundish and with a hard consistency; the maximum diameter was $8.5 \mathrm{~cm}$. The cut surface was grayish and dishomogeneous for the presence of hemorrhagic areas. Histologically, the tumor was composed of bland spindle cells (Figures 1 and 2A). There were no areas of tumor necrosis. Many dilated and thrombosed vessels resembling similar findings seen in neurogenic tumors were intermingled within the tumor cells. Immunocytochemical stains revealed strong cytoplasmic expression of CD117, $D O G 1$, and CD34 (Figure 2B and C). No expression was detected for desmin and S100 protein. c-KIT (exons 9, 11, 13, and 17) and PDGFR $\alpha$ (exons 12, 14, and 18) mutational analyses were performed by bidirectional Sanger sequencing, using BigDye Terminator chemistry, on a 3500 Dx Genetic Analyzer. The test results showed a single mutation in exon 17 of the $c$-KIT gene (pN822K; Figure 3), confirmed in two independent amplifications, while the $P D G F R \alpha$ mutational status
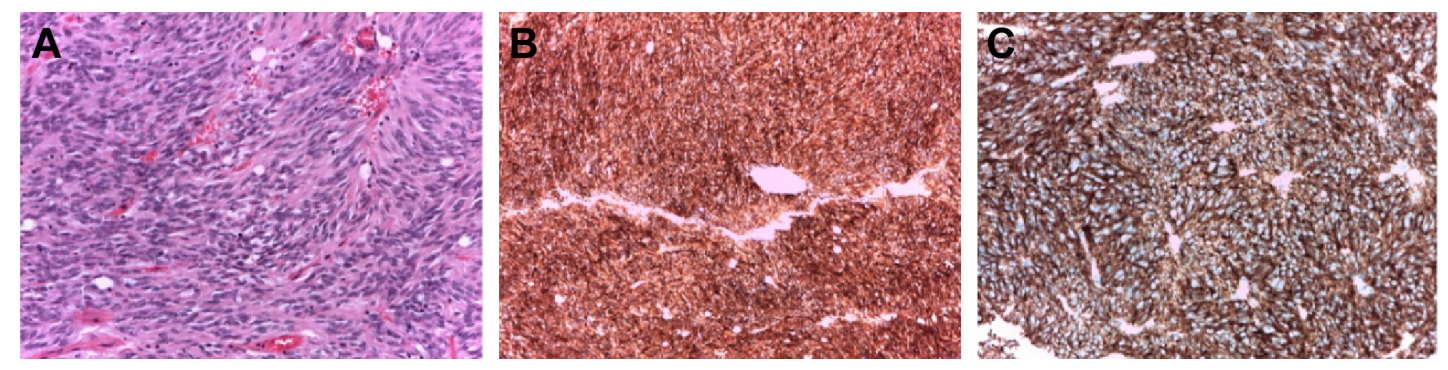

Figure 2 Gastrointestinal stromal tumor cell histology.

Notes: (A) Tumor cells were cytologically bland. No areas of necrosis or atypical mitoses were detected (hematoxylin and eosin stain; original magnification: I0x). (B) Tumor cells expressed strong and diffuse positivity for CDII7 (KIT) (original magnification: 20×). (C) Tumor cells expressed strong and diffuse positivity for DOG-I (original magnification: $20 \times$ ). 


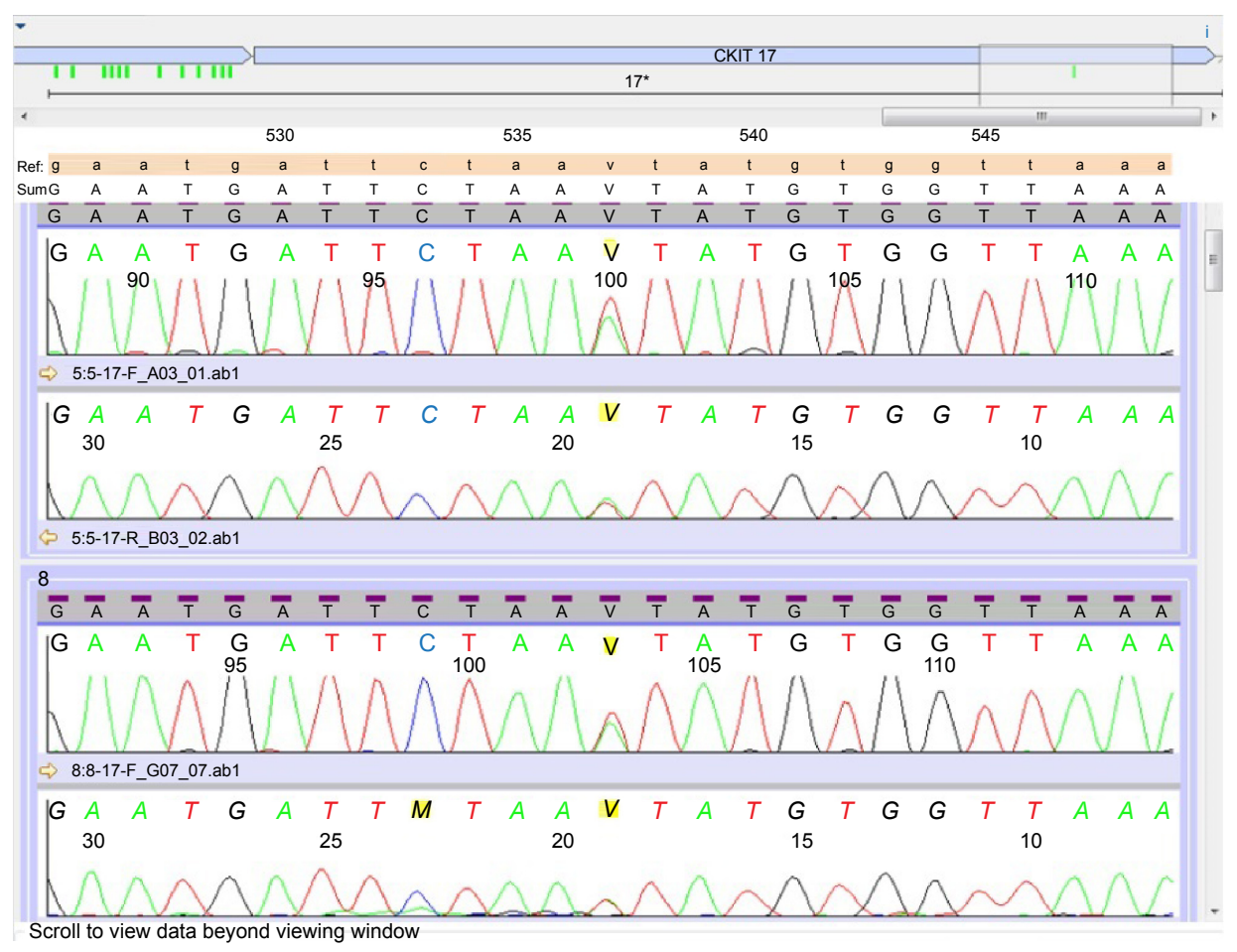

Figure 3 Electropherogram obtained by bidirectional Sanger sequencing of two independent amplifications, both showing a pN822K mutation.

was wild type. Based on the evidence of prior response to imatinib (no tumor shrinkage at instrumental evaluation and no pathological response at the histological report) and the evidence of this rare mutation, treatment with imatinib was not restarted and we decided to begin a clinical-instrumental follow-up every 3-4 months.

At the time of this report, 18 months after surgical resection of the relapsed disease, the patient is still in complete remission.

\section{Discussion}

In this article, we have described the case of a patient affected by a GIST harboring an extremely rare KIT exon 17 mutation, $\mathrm{pN} 822 \mathrm{~K}$, treated with imatinib. The description of this case has significant caveats because we cannot classify this mutation as intrinsic or acquired resistance, since the sample from the first surgery was not available to perform gene sequencing analyses. In our case, the mutation was associated with resistance to imatinib.

The development of GISTs is largely driven by mutations in the KIT and PDGFR $\alpha$ genes. KIT and PDGFR $\alpha$ secondary mutations, or nonsensitive primary mutations, represent the principal cause of resistance to imatinib; other mechanisms can involve the activation of different pathways (eg, $k$-ras and $B R A F){ }^{6,13-17}$
Regarding the epidemiology, mutations affecting the kinase domain in untreated primary resected GISTs are very rare (each $<1 \%$ ), mainly occurring at codon 642 in exon 13 and at codons 816,820 , and 823 in exon $17 .{ }^{18}$ Table 1 depicts the frequency $(0.4 \%-4.5 \%)$ of $c-K I T$ exon 17 mutations, as reported by several retrospective series of imatinib-naïve GIST patients. ${ }^{19-27}$

Very little data are available regarding imatinib sensitivity in GISTs harboring kinase-domain mutations. In a smaller study by Bozzi et al, ${ }^{28}$ it was found that two out 18 imatinib-treated patients had secondary exon 17 KIT mutations (N822K, D816H) associated with exon 11 KIT mutations (dup W577-R586, Ex11:V559A). In a Korean study of 290 patients, ${ }^{29}$ two patients were enrolled with primary exon 17 mutations (A794T and G812D), and both attained a partial response. However, the paper did not report the long-term outcomes of these patients. Conversely, the development of subsequent resistance to imatinib is more frequent, as was demonstrated by a meta-analysis of ten trials ( $>1,000$ patients) ${ }^{30}$ It was shown that the prevalence of second-site KIT or PDGFRA mutations was $61.3 \%$; specifically, the prevalence of exon 17 mutation was the most common, at $54.5 \%$.

In a Phase II study of imatinib conducted with 147 patients with GIST, ${ }^{31}$ molecular analyses were performed 
Table I Frequency of KIT exon 17 mutations in untreated patients with GIST from retrospective studies

\begin{tabular}{|c|c|c|c|c|}
\hline References & Patient (N) & Exon 17 mutations $(\mathrm{N})$ & Type(s) of mutation & Primitive site \\
\hline Subramanian et al ${ }^{19}$ & 26 & I (3.8\%) & N822K & Gastric \\
\hline Wasag et $\mathrm{a}^{20}$ & 28 & I (3.5\%) & N822K & Duodenum \\
\hline Rossi et $\mathrm{al}^{21}$ & 167 & I $(0.6 \%)$ & Not reported & Not reported \\
\hline Arne et $\mathrm{a}^{22}$ & 204 & I $(0.5 \%)$ & Not reported & Not reported \\
\hline Kern et $\mathrm{al}^{23}$ & 95 & $2(2.1 \%)$ & N822K; G826E & Gastric \\
\hline Calabuig-Fariñas et $\mathrm{al}^{24}$ & 154 & $3(1.9 \%)$ & D8I6V; N822K; V823D & Not reported \\
\hline Wozniak et $\mathrm{al}^{25}$ & 427 & $2(0.4 \%)$ & N822K; N822H & Not reported \\
\hline Kang et $\mathrm{al}^{26}$ & 22 & I (4.5\%) & Not reported & Not reported \\
\hline Joensuu et $\mathrm{al}^{27}$ & $\mathrm{I}, 505$ & $10(0.6 \%)$ & Not reported & $6 / 10$ nongastric \\
\hline
\end{tabular}

Abbreviations: GIST, gastrointestinal stromal tumor; N, number.

using samples from ten patients with primary resistance and 33 patients with secondary resistance. Uncommon kinase mutations were most common in GISTs with secondary resistance when compared to those with primary resistance tumors ( $67 \%$ vs $10 \%$, respectively; $P=0.002)$.

Recently, a retrospective analysis of 93 patients treated with neoadjuvant imatinib ${ }^{32}$ showed that exons 9,13 , and 17 mutations were rare, and that they seem to confer a major risk of recurrence.

Two preclinical studies have attempted to predict the association between exon 17 mutations and inhibitor sensitivity, yielding contradictory results. ${ }^{33,34}$ The first study with a xenograft model of GIST harboring an exon $17 \mathrm{D} 816 \mathrm{H}$ mutation has shown a response to intermittent or continuous imatinib treatment; ${ }^{33}$ the second study explored the response of an exon 17 (A818T) knock-in mouse to imatinib, showing that it was refractory. ${ }^{34}$

In the literature, there are a few clinical reports about GISTs harboring exon 17 mutations showing a worse prognosis when treated with imatinib or sunitinib. ${ }^{35-38}$ In 2006, Loughrey et $\mathrm{al}^{35}$ described a case of a female patient affected by small-intestine GIST who progressed after 1 year of treatment of imatinib, and the mutational analysis performed over a peritoneal disease sample revealed a KIT exon 11 , 21 amino acid deletion (identical to that found in the primary tumor) in association with an exon 17 point mutation resulting in an Asn822Lys substitution in the kinase domain. In 2009, a retrospective analysis showed that four out of ten patients refractory to imatinib harbored a mutation in exon 17 (T2467G). ${ }^{36}$ Subsequently, in another retrospective series, a different mutation in exon 17 (Y823D) was found in nine out 18 refractory patients. ${ }^{37}$

In 2010, a case was described of a patient with advanced gastric GIST harboring an exon 11 KIT mutation who, after a 3-year imatinib treatment, developed two new liver lesions harboring two different KIT exon 14 (c.2096C[T]) and KIT exon 17 (c.2554T[G]) mutations with dissociated clinical behavior (both failed to benefit from increasing imatinib dose, while the exon 14 lesion benefited from a sunitinib switch). ${ }^{38}$

Regarding the focus of our report, the exon 17 N822K mutation is extremely rare and, so far, it is associated with unpredictable clinical behavior. Table 2 summarizes the description of all case reports about GIST harboring KIT exon 17 mutation N822K. In 2009, Nishida et $\mathrm{al}^{39}$ reported that four patients with GIST harboring secondary/tertiary exon 17 mutations (D816H, W823D, D822K, plus N822K) did not benefit from sunitinib treatment. In 2011, Hanson et al ${ }^{40}$ described a complex case of a female patient affected from a small-intestine rhabdoid GIST harboring KIT exon 11 579-580 insertion. At the excision of the mass, peritoneal metastases were noted, and she was subsequently treated with 1 year of imatinib. Then, 3 years later, there was an abdominal recurrence harboring an exon 17 N822K mutation, together with an exon 11 mutation. After the excision of the mass, she was treated with 2 years of sunitinib in the absence of a

Table 2 Summary of case reports focusing on KIT exon 17 pN822K mutation

\begin{tabular}{|c|c|c|c|c|}
\hline References & Patient (N) & Primitive site(s) & Type(s) of mutation & Refractory to \\
\hline Nishida et $\mathrm{al}^{39}$ & 4 & Three small intestine; stomach & D8I6H; W823D; D822K; N822K & Imatinib; sunitinib \\
\hline Hanson et $\mathrm{al}^{40}$ & I & Small intestine & $\mathrm{N} 822 \mathrm{~K}$ & Imatinib \\
\hline Gao et $\mathrm{al}^{41}$ & 4 & Not reported & N822K & Imatinib; sunitinib \\
\hline Singeltary et $\mathrm{al}^{42}$ & I & Rectum & N822K & Imatinib; sunitinib \\
\hline Our case & I & Small intestine & N822K & Imatinib \\
\hline
\end{tabular}

Abbreviation: $\mathrm{N}$, number. 
macroscopic evidence of the disease. Later, a third recurrence was excised (sunitinib was given in absence of the macroscopic disease so it cannot be speculated if the disease was responsive to sunitinib) and this did not harbor an exon 17 mutation. The authors speculated that there was a preexisting clone harboring an exon 17 mutation that was selected following imatinib treatment. In 2013, a retrospective analysis of 38 patients who developed imatinib resistance were documented 12 cases with exon 17 mutations (including also N822K mutations), and all the patients with these secondary mutations failed to benefit from switching treatment to sunitinib. ${ }^{41}$

Interestingly, a second case of a 54-year-old white male with a rectal GIST harboring an N822K mutation at c-KIT exon 17 was described. ${ }^{42}$ The patient did not respond to imatinib (neither when administered at $400 \mathrm{mg}$ daily nor at $800 \mathrm{mg}$ daily), nor to sunitinib. After two lines of treatment, a third line was attempted with sorafenib, which resulted in a short-lasting partial response (progression with new lesions at 6-month treatment); so far, it was decided that imatinib be added to sorafenib, attaining 2-year disease stabilization.

This case report documented imatinib resistance in a patient with a rectal GIST harboring a $c-K I T$ N8222K mutation, which was proven both by radiological disease progression and with the absence of pathological features of imatinib response.

\section{Conclusion}

In conclusion, this report suggests that patients with GIST harboring this rare mutation can be resistant to imatinib. Nowadays, sunitinib remains the standard of care for imatinib-refractory GISTs, regardless the status of their secondary KIT mutation. However, genotype analysis showed that patients with a secondary KIT mutation involving the activation-loop domain have poor progression-free survival and overall survival. ${ }^{43,44}$ Novel tyrosine kinase inhibitors (nilotinib, regorafenib, sorafenib) have been tested in preclinical and clinical settings. ${ }^{45-48}$ Two Phase III randomized trials (nilotinib, regorafenib) ${ }^{45,46}$ and two Phase II trials (sorafenib) ${ }^{47,48}$ have shown a modest benefit of these drugs in patients with imatinib/sunitinib-refractory GIST. Subgroup analyses of secondary mutations of KIT were not performed to check if these drugs could be active in the presence of activation-loop domain mutations. A rebiopsy should be encouraged to better define the mechanisms of acquired resistance, and an effort should be made to retrospectively and prospectively analyze the outcomes of patients with GIST harboring rare mutations treated in clinical trials.
Preclinical studies tested the sensitivity of imatinibresistant GIST cells to PKC412 and found that KIT-V654A and PDGFRA-D842 V mutants were sensitive to PKC412. ${ }^{49}$ Indeed, preclinical studies could help to select drugs active for loop domain mutations: a molecular modeling analysis showed that the fragment deletion of exon 11 and the point mutation on exon 17 would lead to a shift of KIT conformational equilibrium toward an active form, for which nilotinib and sorafenib bind with higher affinity than imatinib and sunitinib; thus far, they could be tested in these settings. ${ }^{50}$

\section{Acknowledgment}

The authors thank Mr William Russell-Edu for help with English editing. The authors' local Ethical committee approved this retrospective study, and patients provided informed consent.

\section{Author contributions}

All authors contributed toward data analysis, drafting and revising the paper and agree to be accountable for all aspects of the work.

\section{Disclosure}

None of the authors, nor the European Institute of Oncology, received any payment or support in kind for any aspect of the submitted work. The authors report no conflicts of interest in this work.

\section{References}

1. Nilsson B, Bümming P, Meis-Kindblom JM, et al. Gastrointestinal stromal tumors: the incidence, prevalence, clinical course, and prognostication in the preimatinib mesylate era - a population-based study in western Sweden. Cancer. 2005;103(4):821-829.

2. Corless CL. Gastrointestinal stromal tumors: what do we know now? Mod Pathol. 2014;27 Suppl 1:S1-S16.

3. Miettinen M, Lasota J. Gastrointestinal stromal tumors (GISTs): definition, occurrence, pathology, differential diagnosis and molecular genetics. Pol J Pathol. 2003;54(1):3-24.

4. Kindblom LG, Remotti HE, Aldenborg F, Meis-Kindblom JM. Gastrointestinal pacemaker cell tumor (GIPACT): gastrointestinal stromal tumors show phenotypic characteristics of the interstitial cells of Cajal. Am J Pathol. 1998;152(5):1259-1269.

5. West RB, Corless CL, Chen X, et al. The novel marker, DOG1, is expressed ubiquitously in gastrointestinal stromal tumors irrespective of KIT or PDGFRA mutation status. Am J Pathol. 2004;165(1):107-113.

6. Debiec-Rychter M, Sciot R, Le Cesne A, et al; EORTC Soft Tissue and Bone Sarcoma Group; Italian Sarcoma Group; Australasian GastroIntestinal Trials Group. KIT mutations and dose selection for imatinib in patients with advanced gastrointestinal stromal tumours. Eur J Cancer. 2006;42(8):1093-1103.

7. Corless CL, Schroeder A, Griffith D, et al. PDGFRA mutations in gastrointestinal stromal tumors: frequency, spectrum and in vitro sensitivity to imatinib. J Clin Oncol. 2005;23(23):5357-5364.

8. Heinrich MC, Griffith DJ, Druker BJ, Wait CL, Ott KA, Zigler AJ. Inhibition of c-kit receptor tyrosine kinase activity by STI 571, a selective tyrosine kinase inhibitor. Blood. 2000;96(3):925-932. 
9. Demetri GD, von Mehren M, Blanke CD, et al. Efficacy and safety of imatinib mesylate in advanced gastrointestinal stromal tumors. $N$ Engl J Med. 2002;347(7):472-480.

10. von Mehren M, Heinrich MC, Joensuu H, Blanke CD, Wehrle E, Demetri D. Follow-up results after 9 years (yrs) of the ongoing, phase II B2222 trial of imatinib mesylate (IM) in patients (pts) with metastatic or unresectable KIT+ gastrointestinal stromal tumors (GIST) [abstract]. J Clin Oncol. 2011;29(Suppl):abstr 10016.

11. Corless CL, Ballman KV, Antonescu CR, et al. Pathologic and molecular features correlate with long-term outcome after adjuvant therapy of resected primary GI stromal tumor: the ACOSOG Z9001 trial. J Clin Oncol. 2014;32(15):1563-1570.

12. Verweij J, Casali PG, Zalcberg J, et al. Progression-free survival in gastrointestinal stromal tumours with high-dose imatinib: randomised trial. Lancet. 2004;364(9440):1127-1134.

13. Heinrich MC, Corless CL, Demetri GD, et al. Kinase mutations and imatinib response in patients with metastatic gastrointestinal stromal tumor. J Clin Oncol. 2003;21(23):4342-4349.

14. Debiec-Rychter M, Wasag B, Stul M, et al. Gastrointestinal stromal tumours (GISTs) negative for KIT (CD117 antigen) immunoreactivity. J Pathol. 2004;202(4):430-438.

15. Gastrointestinal Stromal Tumor Meta-Analysis Group (MetaGIST). Comparison of two doses of imatinib for the treatment of unresectable or metastatic gastrointestinal stromal tumors: a meta-analysis of 1,640 patients. J Clin Oncol. 2010;28(7):1247-1253.

16. Heinrich MC, Owzar K, Corless CL, et al. Correlation of kinase genotype and clinical outcome in the North American Intergroup Phase III Trial of imatinib mesylate for treatment of advanced gastrointestinal stromal tumor: CALGB 150105 Study by Cancer and Leukemia Group B and Southwest Oncology Group. J Clin Oncol. 2008;26(33):5360-5367.

17. Miranda C, Nucifora M, Molinari F, et al. KRAS and BRAF mutations predict primary resistance to imatinib in gastrointestinal stromal tumors. Clin Cancer Res. 2012;18(6):1769-1776.

18. Lasota J, Corless CL, Heinrich MC, et al. Clinicopathologic profile of gastrointestinal stromal tumors (GISTs) with primary KIT exon 13 or exon 17 mutations: a multicenter study on 54 cases. Mod Pathol. 2008;21(4):476-484.

19. Subramanian S, West RB, Corless CL, et al. Gastrointestinal stromal tumors (GISTs) with KIT and PDGFRA mutations have distinct gene expression profiles. Oncogene. 2004;23(47):7780-7790.

20. Wasag B, Debiec-Rychter M, Pauwels P, et al. Differential expression of KIT/PDGFRA mutant isoforms in epithelioid and mixed variants of gastrointestinal stromal tumors depends predominantly on the tumor site. Mod Pathol. 2004;17(8):889-894.

21. Rossi S, Gasparotto D, Toffolatti L, et al. Molecular and clinicopathologic characterization of gastrointestinal stromal tumors (GISTs) of small size. Am J Surg Pathol. 2010;34(10):1480-1491.

22. Arne G, Kristiansson E, Nerman O, et al. Expression profiling of GIST: CD133 is associated with KIT exon 11 mutations, gastric location and poor prognosis. Int J Cancer. 2011;129(5):1149-1161.

23. Kern A, Görgens H, Dittert DD, et al. Mutational status of KIT and PDGFRA and expression of PDGFRA are not associated with prognosis after curative resection of primary gastrointestinal stromal tumors (GISTs). J Surg Oncol. 2011;104(1):59-65.

24. Calabuig-Fariñas S, López-Guerrero JA, Navarro S, et al. Evaluation of prognostic factors and their capacity to predict biological behavior in gastrointestinal stromal tumors. Int J Surg Pathol. 2011;19(4):448-461.

25. Wozniak A, Rutkowski P, Piskorz A, et al; Polish Clinical GIST Registry. Prognostic value of KIT/PDGFRA mutations in gastrointestinal stromal tumours (GIST): Polish Clinical GIST Registry experience. Ann Oncol. 2012;23(2):353-360.

26. Kang G, Lee J, Jang KT, et al. Multiplex mutation screening by mass spectrometry in gastrointestinal stromal tumours. Pathology. 2012;44(5):460-464.

27. Joensuu H, Rutkowski P, Nishida T, et al. KIT and PDGFRA mutations and the risk of GI stromal tumor recurrence. J Clin Oncol. 2015; 33(6):634-642.
28. Bozzi F, Conca E, Manenti G, et al. High CD133 expression levels in gastrointestinal stromal tumors. Cytometry B Clin Cytom. 2011;80(4): 238-247.

29. Kang HJ, Ryu MH, Kim KM. Imatinib efficacy by tumor genotype in Korean patients with advanced gastrointestinal stromal tumors (GIST): The Korean GIST Study Group (KGSG) study. Acta Oncol. 2012;51(4):528-536.

30. Lee JH, Kim Y, Choi JW, Kim YS. Correlation of imatinib resistance with the mutational status of KIT and PDGFRA genes in gastrointestinal stromal tumors: a meta-analysis. J Gastrointestin Liver Dis. 2013; 22(4):413-418.

31. Heinrich MC, Corless CL, Blanke CD, et al. Molecular correlates of imatinib resistance in gastrointestinal stromal tumors. J Clin Oncol. 2006; 24(29):4764-4774.

32. Bednarski BK, Araujo DM, Yi M, et al. Analysis of prognostic factors impacting oncologic outcomes after neoadjuvant tyrosine kinase inhibitor therapy for gastrointestinal stromal tumors. Ann Surg Oncol. 2014;21(8):2499-2505.

33. Revheim ME, Kristian A, Malinen E, et al. Intermittent and continuous imatinib in a human GIST xenograft model carrying KIT exon 17 resistance mutation D816H. Acta Oncol. 2013;52(4):776-782.

34. Ishikawa $\mathrm{T}$, Nakai $\mathrm{N}$, Liu NN, et al. In vivo effect of imatinib on progression of cecal GIST-like tumors in exon 17-type c-kit knock-in mice. Lab Invest. 2009;89(10):1161-1168.

35. Loughrey MB, Beshay V, Dobrovic A, Zalcberg J, Waring PM. Pathological response of gastrointestinal stromal tumour to imatinib treatment correlates with tumour KIT mutational status in individual tumour clones. Histopathology. 2006;49(1):99-100.

36. Wang CM, Fu H, Zhao GF, et al. Secondary resistance to imatinib in patients with gastrointestinal stromal tumors through an acquired KIT exon 17 mutation. Mol Med Rep. 2009;2(3):455-460.

37. Wang CM, Huang K, Zhou Y, et al. Molecular mechanisms of secondary imatinib resistance in patients with gastrointestinal stromal tumors. J Cancer Res Clin Oncol. 2010;136(7):1065-1071.

38. Cameron S, Savvoukidis T, Armbrust T, et al. Analysis of a case with disappearance of the primary gastrointestinal stromal tumor and progressive liver metastases under long-term treatment with tyrosine kinase inhibitors. Med Oncol. 2010;27(2):213-218.

39. Nishida T, Takahashi T, Nishitani A, et al; Japanese Study Group on GIST. Sunitinib-resistant gastrointestinal stromal tumors harbor cismutations in the activation loop of the KIT gene. Int J Clin Oncol. 2009; 14(2):143-149.

40. Hanson JA, Trent JC, Yang D, Cooper K. Small-intestinal rhabdoid gastrointestinal stromal tumor (GIST): mutation analysis and clinical implications of a rare morphological variant. Int J Surg Pathol. 2011; 19(5):653-657.

41. Gao J, Tian Y, Li J, Sun N, Yuan J, Shen L. Secondary mutations of c-KIT contribute to acquired resistance to imatinib and decrease efficacy of sunitinib in Chinese patients with gastrointestinal stromal tumors. Med Oncol. 2013;30(2):522.

42. Singeltary B, Ghose A, Sussman J, Choe K, Olowokure O. Durable response with a combination of imatinib and sorafenib in KIT exon 17 mutant gastrointestinal stromal tumor. J Gastrointest Oncol. 2014;5(1): E27-E29.

43. Demetri GD, van Oosterom AT, Garrett CR, et al. Efficacy and safety of sunitinib in patients with advanced gastrointestinal stromal tumour after failure of imatinib: a randomised controlled trial. Lancet. 2006;368(9544): 1329-1338.

44. Heinrich MC, Maki RG, Corless CL, et al. Primary and secondary kinase genotypes correlate with the biological and clinical activity of sunitinib in imatinib-resistant gastrointestinal stromal tumor. J Clin Oncol. 2008;26(33):5352-5359.

45. Reichardt P, Blay JY, Gelderblom H, et al. Phase III study of nilotinib versus best supportive care with or without a TKI in patients with gastrointestinal stromal tumors resistant to or intolerant of imatinib and sunitinib. Ann Oncol. 2012;23(7):1680-1687. 
46. Demetri GD, Reichardt P, Kang YK, et al; GRID study investigators. Efficacy and safety of regorafenib for advanced gastrointestinal stromal tumours after failure of imatinib and sunitinib (GRID): an international, multicentre, randomised, placebo-controlled, phase 3 trial. Lancet. 2013;381(9863):295-302.

47. Park SH, Ryu MH, Ryoo BY, et al. Sorafenib in patients with metastatic gastrointestinal stromal tumors who failed two or more prior tyrosine kinase inhibitors: a phase II study of Korean gastrointestinal stromal tumors study group. Invest New Drugs. 2012;30(6):2377-2383.

48. Kindler HL, Campbell NP, Wroblewski K, et al. Sorafenib (SOR) in patients (pts) with imatinib (IM) and sunitinib (SU)-resistant (RES) gastrointestinal stromal tumors (GIST): final results of a University of Chicago Phase II Consortium trial [abstract]. J Clin Oncol. 2011;29(Suppl):abstr 10009.
49. Debiec-Rychter M, Cools J, Dumez H, et al. Mechanisms of resistance to imatinib mesylate in gastrointestinal stromal tumors and activity of the PKC412 inhibitor against imatinib-resistant mutants. Gastroenterology. 2005;128(2):270-279.

50. Hsueh YS, Lin CL, Chiang NJ, et al. Selecting tyrosine kinase inhibitors for gastrointestinal stromal tumor with secondary KIT activation-loop domain mutations. PLoS One. 2013;8(6):e65762.

\section{Publish your work in this journal}

OncoTargets and Therapy is an international, peer-reviewed, open access journal focusing on the pathological basis of all cancers, potential targets for therapy and treatment protocols employed to improve the management of cancer patients. The journal also focuses on the impact of management programs and new therapeutic agents and protocols on

\section{Dovepress}

patient perspectives such as quality of life, adherence and satisfaction. The manuscript management system is completely online and includes a very quick and fair peer-review system, which is all easy to use. Visit http://www.dovepress.com/testimonials.php to read real quotes from published authors.

Submit your manuscript here: http://www.dovepress.com/oncotargets-and-therapy-journal 